\title{
Antimicrobials Use in Aquaculture and their Public Health Impact
} Salah Mesalhy Aly ${ }^{1^{*}}$ and Aqel Albutti ${ }^{2}$

${ }^{1}$ Department of Pathology, Faculty of Veterinary Medicine, Suez Canal University, Egypt

${ }^{2}$ Medical Laboratories Department; Faculty of Applied Medical Sciences; Qassim University, Kingdom of Saudi Arabia

*Corresponding author: Salah Mesalhy Aly, Department of Pathology, Faculty of Veterinary Medicine, Suez Canal University, Egypt, Tel: 201212789838; E-mail: salahaly@hotmail.com

Rec date: April 03, 2014; Acc date: July 14, 2014; Pub date: July 22, 2014

Copyright: () 2014 Aly SM. This is an open-access article distributed under the terms of the Creative Commons Attribution License, which permits unrestricted use, distribution, and reproduction in any medium, provided the original author and source are credited.

\begin{abstract}
Diseases are one of these primary limiting factors. Bacterial diseases are responsible for heavy mortality in both wild and cultured fish. Antibiotics used to control such infection and misuse as well as other sources of antimicrobials as using chicken manure or adoption of integrating fish system may emerge the development and spread of antimicrobial resistant bacteria and resistance genes and occurrence of antimicrobial residues. All that may induce a negative impact on human, fish and the environment. Aquaculture has become the fastest growing sector of food production in the world. Despite the encouraging trends, several constraints have negative impact on the growth of aquaculture. Therefore, strict measures, legislations and regulations for the use of antimicrobials in aquaculture should be developed and implemented, especially in developing countries, to avoid such negative impacts in human, fish, animals and environment. These consequences, in human, include increased number of infections, increased frequency of treatment failures and increased severity of infection that result a prolonged duration of illness, increased frequency of bloodstream infections, increased hospitalization, and increased mortality.
\end{abstract}

Keywords: Antimicrobials; Aquaculture; Disease resistance; Human health

\section{Global Aquaculture}

Aquaculture appears to be one of the last frontiers to increase contributions to food security in the developing world. It now represents the fastest growing agricultural industry in some countries, with freshwater aquaculture dominating total aquaculture production. This global picture is reflected in Africa where aquaculture supply high quality food at low cost to millions of people, generate income for farming and fishing households and play a central role in many local and national economies $[1,2]$.

Capture fisheries and aquaculture supplied the world with about 148 million tons of fish in 2010 (with a total value of US\$217.5 billion), where about 128 million tones was utilized as food for people, and preliminary data for 2011 indicate increased production to145 million tones, among those 131 million tones was destined as food. With sustained growth in fish production and improved distribution channels, world fish supply has grown dramatically in last five decades, with average rate of 3.2 percent per year in the period 1961-2009, outpacing the increase of 1.7 percent per year in the world's population. World per capita food fish supply increased from an average of $9.9 \mathrm{~kg}$ (live weight equivalent) in 1960 to $18.4 \mathrm{~kg}$ in 2009 , and preliminary estimates for 2010 point to a further increase in fish consumption to $18.6 \mathrm{~kg}$. Out of 126 million tones available for human consumption in 2009, fish consumption was lowest in Africa (9.1 million tones, with $9.1 \mathrm{~kg}$ per capita), while Asia accounted for twothirds of total consumption, of 85.4 million tones (20.7 kg per capita), where 42.8 million tons were consumed outside China (15.4 per capita) [2]. Aquaculture has grown at an average rate of 8.9 percent per year since 1970. Total fish production in the Arab World in 2012 amounted 3.09 million tons representing $2.2 \%$ of world fish production in the same year whereas seven Arab countries collectively produced $88.2 \%$ of total fish production in the Arab world. Egypt is one of major Arab fish producing countries (28.8\%). Although most of aquaculture technologies are now in practice in the Arab World, commercial aquaculture only exists in few countries whereas $91.9 \%$ of Arab aquaculture is produced in Egypt. Total aquaculture production in the Arab world amounted 587195 tons in 2012 representing only $1.23 \%$ of global aquaculture in that year.

\section{Aquaculture Obstacles}

There are some challenges facing the development of aquaculture, especially the challenges related to the use of natural resources (water and land). There are other constraints related to the limited availability of production inputs, the limited impact of research and extension, the lack and/or insufficient credits, and the competition with other sectors regarding the use of main resources. The challenges facing aquaculture development is currently changed from production orientation to quality orientation. Similarly, sustainable aquaculture production that considers environmental, economic and social issues is far important than quantity oriented aquaculture.

The species is classified within the opportunistic omnivorous fish category and consume a variety of food resources, ranging from aquatic invertebrates to small seeds, including small benthic organisms, fishes, shrimps, plant remains and terrestrial insects. In captivity, remarkable growth performances have been reported, individual mean body mass reaching up to 3 to $4 \mathrm{~kg}$ in 12 months. However, its use for profitable fish-farming in Africa relies on the knowledge of ecological, behavioral and nutritional factors which condition its reproduction, the resolution of massive mortality during early ontogeny, the estimate of its nutritional needs at various ontogenetic stages and the identification of an efficient breeding. The prospect for Heterotis contribution to the rise of African aquaculture 
depends on the solutions which will be found to the mentioned crucial problems.

Despite the encouraging trends, diseases are one of constraint have negative impact on the growth of aquaculture. Although global economic losses from diseases in aquaculture have not been compiled, reports from many regions of the world have been increasing with advances in the live aquatic animal trade [3].

\section{Antibiotics Use}

Antibiotics are used in aquaculture as a prophylactive or therapuetic measures or as feed additives and gain access to the pond environment through using human and animal wastes or integrated fish farming system. There has been a surge in the number of foodborne infections caused by antibiotic resistant bacteria (ARB) [4]. Recently, a few studies have shown a direct relationship between antibiotic use in food animals and the emergence of antibiotic resistance in human and animal pathogens $[5,6]$.

Although, bacterial diseases are controlled in some situations by eradication, maintenance of animals of specified health status, vaccination, and good hygiene, nevertheless, antimicrobial chemotherapy remains vitally important for treating and in some cases preventing some bacterial diseases [7]. Appropriate use of antimicrobials will cure some sick animals and speed the recovery of others, and improves the welfare of treated animals and reduce the spread of infection to other animals or, in the case of zoonotic disease to humans. The challenge is how to use antimicrobials wisely and minimizing the risk of resistance [8].

Prophylactic use of antimicrobials is more common in veterinary practice than in human medicine and reflects husbandry systems where animals are contained in close proximity within the same patch of air or water. Group medication in these circumstances involves the therapeutic treatment of affected animals and prophylactic medication of unaffected contacts. The antimicrobials are administered at therapeutic dosage, which clearly differentiates this strategy from that used to enhance production.

The use of antibiotics as feed additives in food animals has been cited as one of the reasons for the development of antibiotic resistant bacteria (ARB) in the environment. Antibiotics are selected for antibiotic resistant bacteria in the gut of the animal and in the terrestrial environment when antibiotic laden manure and urine are applied to the land [9]. Antibiotics fed at low, generally subtherapeutic concentrations are known to improve feed conversion efficiency and thus performance in food producing animals. The improvement reflects a reduction in subclinical disease, although this is probably not the whole reason [10].

\section{Other Sources for Antimicrobials}

In many developing countries the use of antimicrobial drugs for treating people and animals is unregulated; antibiotics can be purchased in pharmacies, general stores, and even market stalls [11]. Antibiotic resistance and possible treatment failures in animal production are becoming a fast growing preoccupation involving diverse agricultural industries and species. The problem is no different in the aquaculture industry where resistance development has been reported in freshwater and marine environments [12,13].

The addition of manure into the fish ponds release inorganic nutrients that supports the growth of photosynthetic organisms, which are then eaten by the fish. The animal feed often contains antimicrobials, which are added to promote growth or to treat or prevent diseases [14]. Thus, antimicrobials and antimicrobial-resistant bacteria enter the fish ponds and are established in fish. Moreover, the direct medication of fish in fresh water aquaculture leads to an increase in the level of antimicrobial resistance among bacteria in the fish intestine [15].

However, the input of animal manure into integrated fish farms could be associated with a higher occurrence of antimicrobial-resistant bacteria which might reflect on fish quality and shelf-life as well as consumers. Therefore, there is a need for investigating the conditions in the aquaculture environment [16].

Human and animal wastes have traditionally been used in Asia as sources of fertilizer for fish culture ponds [17]. The use of waste stabilization ponds is common throughout the world. Moreover, integrated fish farming is also practiced throughout southeast Asia. Manure from livestock production is administered to fish ponds; the manure is either directly consumed by fish, or release of nutrients that supports the growth of mainly photosynthetic organisms [18]. This integrated fish farming system produces high yields with low input, with the fish receiving limited, if any, supplementary feed. In contrast, the livestock on the integrated farms, which includes chickens and pigs, is reared intensively, and antimicrobial agents are used as growth promoters and for prophylactic and therapeutic treatment.

Within integrated fish farming systems, antimicrobials, their residues, and antimicrobial-resistant bacteria enters the fish ponds through animal manure and/or excess feeding and are potential sources of antimicrobial-resistant bacteria. However, the impact of the use of animal manure in integrated fish farm environments on the occurrence of antimicrobial resistant bacteria has to our knowledge not been investigated previously.

Antimicrobial resistance in traditional fish farming systems in temperate waters has been intensively studied [19]. A high incidence of bacteria resistant to the antimicrobials used in aquaculture, including multiply resistant bacteria, has been found in fish farms and the surrounding aquatic environments [20,21]. Furthermore, residues of antimicrobials have been found in the sediments of marine fish farms [22] (Figure 1).

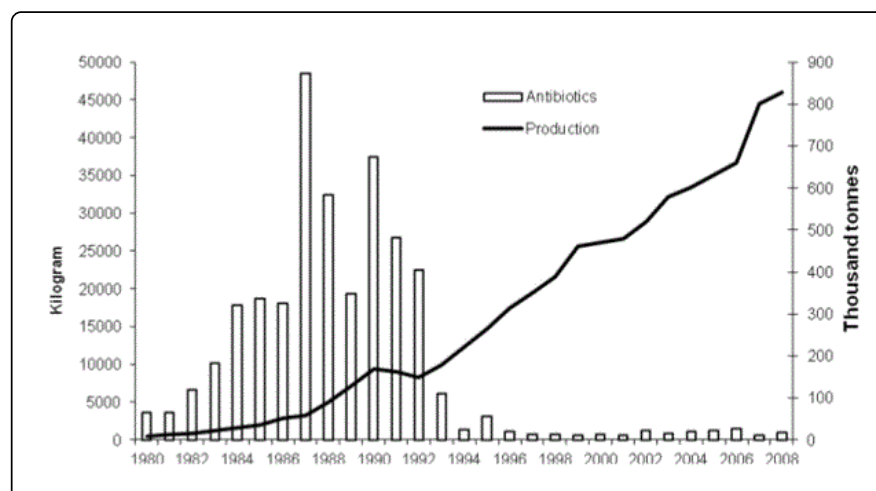

Figure 1: Production \& antibiotics use in aquaculture.

Today, development and spread of antimicrobial resistance has become a global public health problem that is impacted by both human and non-human antimicrobial usage [23]. Furthermore, the use of antimicrobials in one ecological niche, such as in aquaculture, 
Page 3 of 6

can have impact on the resistance situation in another ecological niche, such as human medicine, and resistance problems in one country can spread to another country [24].

Antimicrobial usage in aquaculture can result in residues of antimicrobials in seafood. Such antimicrobial residues can present a hazard to public health if the consumer becomes exposed to the residues, either through the consumption of seafood containing residues, or by the handling of products containing residues.

Such environmental contamination with antimicrobial residues of antimicrobials in the aquatic environment can have a negative impact on the environment, e.g. by altering the microflora, which again indirectly can have a negative effect on public health. Such environmental contamination with antimicrobial can select for resistance in environmental microflora, and resistance genes can be disseminated further and eventually reach e.g. human pathogens.

Aquatic environments can be a source of resistant bacteria that can be transmitted to and cause infections in humans, and due to the resistance traits results in treatment failures. Such direct spread of resistance from aquatic environments to humans may involve human pathogens such as Vibrio cholerae, Vibrio parahaemolyticus, Vibrio vulnificus, Shigella spp. and Salmonella spp. or opportunistic pathogens such as Aeromonas hydrophila, Plesiomonas shigelloides, Edwardsiella tarda, Streptococcus iniae and E. coli. The spread of such resistant bacteria to humans may be through direct contact with water or aquatic organisms, through drinking water or through the handling or consumption of seafood. Approximately $80 \%$ of antimicrobials used in aquaculture enter the environment where they select for bacteria whose resistance arises from mutations or more importantly, from mobile genetic elements containing multiple resistance determinants transmissible to other bacteria. Such selection alters biodiversity in aquatic environments and the normal flora of fish and shellfish. The presence terrestrial bacteria in aquatic environment together with the presence of residual antimicrobials, biofilms, and high concentrations of bacteriophages with pathogens of human and animal origin can allow exchange of genetic materials between aquatic and terrestrial bacteria. Several recently found genetic elements and resistance determinants for quinolones, tetracyclines, and b-lactamases are shared between aquatic bacteria, fish pathogens, and human pathogens, and appear to have originated in aquatic bacteria [25].

The consequences of antimicrobial resistance in bacteria causing human infections include increase number of infections, frequency of treatment failures and severity of infection, and finally increased costs to society associated with disease. Increased severity of infection includes prolonged duration of illness, increase frequency of bloodstream infections, hospitalization and mortality [22].

\section{Needs of Assessment}

FAO/WHO/OIE [15] have identified the gaps and needs for future research to minimize the antimicrobial use in aquaculture that summarized in the following:

- There is a need for more knowledge on consumption of seafood in various regions and different subpopulations.

- There is a need for more regional data on prevalence of antimicrobial resistance in various bacteria and different production types.

- There is a need to increase the availability of accurate diagnostic services at regional and farms levels.
- There is a need for better regional data on usage of different antimicrobials in different production types.

- There is a need for more regional data on the occurrence of residues of various antimicrobials in different production types.

- There is a need for more knowledge on spread of resistance genes from aquatic bacteria and fish bacteria to human pathogens.

- There is a need to support and assist developing countries in their efforts regarding implementation of preventive measures (hygiene, environmental conditions, vaccines), implementation of prudent use guidelines, regulatory control of antimicrobial usage and monitoring of antimicrobial use and antimicrobial resistance.

- Antibiotics are valuable medicines, and should be used only therapeutically and as little as necessary. It is important that national veterinary, agricultural and pharmaceutical authorities promote preventive veterinary medicine and the prudent use of antibiotics in collaboration with the private sector and all relevant stakeholders, particularly veterinary practitioners and farmers. Particularly important steps are: reducing the need for antibiotics in animal husbandry by improving animal health through biosecurity measures, disease prevention; including the introduction of effective vaccines, use of immunostimulants and probiotics [26,27], and good hygienic and management practices; and eliminating economic incentives that facilitate the inappropriate prescription of antibiotics.

\section{Guidelines for Using Chemotherapy}

- The best treatment of all is good animal husbandry.

- Drugs and chemicals are often used to correct errors in management.

- Indiscriminant uses of therapeutic agents should be avoided.

- The continuous feeding at low levels of antibiotics in the diet as a prophylactic measure against outbreaks of bacterial disease during periods of stress, or to improve growth rates are questionable practices.

- Indiscriminant feeding of low levels of antibiotics will remove only those bacteria most sensitive to the drug and can lead to the development of drug resistant strains.

- Drug resistant bacteria can transmit this resistance to different species of bacteria that have never been exposed to the drug.

- Therefore, treatment with antibiotics is recommended only when needed, and then only at prescribed treatment levels.

- If a decision to use antibiotics is made, treatment should be conducted for the full time period required. Shorter treatments will also encourage the development of drug resistance and can lead to the need for elevated drug levels, and eventually to loss of effectiveness.

- The casual use of therapeutics on a routine basis is not without possible adverse effects on the general health of the fish and is not recommended,

- Whenever possible, seek a positive diagnosis of any disease problem by a professional fish health specialist.

- Start treatment with the correct drug at the recommended level.

- If a chemotherapeutant is needed, treat quickly and effectively.

- Users are advised to proceed with caution and to follow label directions.

- Recommended rates of treatment are based on the levels that researches have found to be necessary and that various fishes will tolerate. 
Page 4 of 6

- Although there is a built-in safety factor, using more than the recommended rate is not necessarily, may be harmful, and may be illegal.

- Two weeks withdrawal, from all chemotherapeutic treatments before the intended release date, is recommended. If fish are being reared for human food, sale of the carcasses may not be allowed if drug residues are found in the fish.

\section{Guidelines for Chemoptherapy Application}

\section{Before treatment}

- Ensure that information on chemical characteristics of the water supply is available.

- Ascertain how they will affect the toxicity and efficacy of the treatment.

- What will work at one place may not be effective elsewhere for differences in water chemistry.

- Before using any chemical, be sure to test it first on a small number of sick fish.

- Keep in mind that, healthy fish can tolerate chemical treatment more readily than sick fish and that treatment levels may need to be reduced if the fish are weak or in poor condition.

- Ensure that, rearing facilities are clean. Dirty raceways or tanks may contain organic matter that will absorb part of the treatment chemical and reduce its effectiveness.

- If the fish density is excessive, it should be reduced, if possible, prior to static treatment. Supplemental aeration should be provided, if needed.

- During hot weather, treatments should be made during the coolest part of the day using chemicals that create the least environmental hazard or stress.

- Starving fish 1-2 days prior to treatment will reduce their oxygen consumption, ammonia production, and will increase resistance to scale loss. Never treat within $4 \mathrm{hrs}$ after feeding.

- Any parasitism of the gills should be treated first since such parasites may affect respiratory capability of the fish.

- Monitor dissolved oxygen levels before treatment. Fish are stressed during treatment and increase their need for oxygen.

- Before treating with a new compound or formulation or using a product for the first time on an installation, always treat a small group of fish first and watch for unexpected mortality.

\section{During treatment}

- Always observe fish during treatment to watch for signs of stress or unexpected toxicity.

- Monitor dissolved oxygen levels during treatment. Fish are stressed during treatment and increase their need for oxygen.

- Always check your calculations (0.1X will be ineffective; 1.0 is effective; but $10 \mathrm{X}$ will be fatal). If possible, have someone check your figures.

\section{After treatment}

- Keep records of all treatments, their purpose, and the results for future reference.

\section{Methods for Antimicrobials Application}

\section{Treatment in the diet}

If available, commercial feed with antibiotic additives is cheap and easy to use. Medicated feed stores well and can be used in place of the regular diet. If commercially medicated feed is not available, medicated feed can be prepared on site. Antibiotics, such as oxytetracycline (Terramycin), which are water soluble may leach out of the feed unless preventive steps are taken. It is best to suspend such drugs in oil when preparing medicated feed (cod liver oil seems to have better palatability than soy bean or corn oils, but any of these will do).

\section{Localized applications}

External: Localized skin applications are feasible only for broodstock and other valuable fish. The drug used should be relatively insoluble in water, act on contact, and either be denser than water or so adhesive that the fish can't rub it off.

Internal: For small numbers of valuable fish, injections of antibiotics can be used but may be very expensive and labor intensive. Intraperitoneal injection is superior to subcutaneous or intramuscular injections. If possible, the fish should be immobilized by holding it in the web of a large mesh net. If struggling causes scale losses or injury, or if the fish are simply too large to handle, it may be best to anesthetize the animals. Both MS-222 (tricaine methanesulfonate) and carbon dioxide have been used with success for this purpose. Injections of drugs require small syringes and use a 20 to 26 gauge needle depending on the size of the fish. Insert the needle through the body wall just posterior to the pelvic girdle at a shallow angle until resistance suddenly ceases. Avoid puncturing the intestine or gonads by inserting the needle too far.

Bath treatments: Dipping the fish involves a short bath treatment with a duration varying from only a few seconds to $5 \mathrm{~min}$ (dip bath) or up to $1 \mathrm{~h}$ (short bath), depending on the chemical and concentration used. It is recommended to use wood tubs but plastic avoids possible chemical reactions between galvanized metal and treatment chemicals, which may be toxic to the fish. Dip treatments are often used on broodstock. They are effective but can be highly stressful.

\section{Factors Affecting Antibiotics Use}

Antibiotics are very useful additions to any fish health manager's toolbox, but they are only tools and not "magic bullets". The ability of antibiotics to help eliminate a fish disease depends on a number of factors:

- Does the problem actually have a bacterial component?

- Are the bacteria involved sensitive to the antibiotic chosen?

- Are the proper dosage and treatment intervals being used?

- Have other contributing stresses been removed or reduced?

\section{Antibiotics do not Cure the Fish Alone}

- Antibiotics merely control the population of bacteria in a fish long enough for its immune system to eliminate them.

- Before antibiotics are even considered, sources of stress such as poor water quality (including drastic temperature change), nutrition, genetics, and handling or transport must be removed or reduced. 
- Affected fish should also be examined for parasites.

- Any of these factors may be the primary cause of disease, as bacterial infections are often secondary to such management problems.

- Contacting a fish health specialist early in the disease outbreak will help identify contributing stresses and the rate of bacterial infection so total losses of fish will be reduced.

\section{Fighting Bacterial Infections}

The ideal solution to bacterial diseases involves working with a fish health specialist to culture the organism and to run sensitivity tests. Although culture and sensitivity tests generally take two or three days, they are, by far, the best methods for selecting an antibiotic that will successfully and economically treat an infection. A fish health specialist should provide instructions on submitting samples to a diagnostic laboratory where [28]:

- Affected fish should not be treated with any antibiotic until after a sample has been analyzed.

- The sample should include at least 3 to 5 fish showing typical symptoms of the disease.

- Fish that are submitted after they have been given antibiotics often provide poor culture results.

- While waiting for the culture results, the fish health specialist may suggest a broad-spectrum antibiotic that can be used until culture and sensitivity tests have been completed.

- Legalities must also be considered when selecting antibiotics.

- Your fish health specialist will be able to provide information on legal constraints for specific antibiotics, information for correct dosages, proper methods of administration, and other concerns.

\section{Proper Treatment}

Although selecting the correct antibiotic is an important first step in controlling bacterial disease, proper administration of any antibiotic for the recommended number of days is equally important where [29]:

- Fish health specialist should provide instructions on the amount of antibiotic to use (dose), the frequency (how often) and duration (how long).

- Withdrawal time (time required, after the last dose of antibiotic has been given, till selling the fish) should be known.

- The pharmacokinetics of a specific antibiotic should be determined.

\section{Combining Antibiotics}

- Combining different antibiotics is generally not recommended.

- Antibiotics work at many different sites on and in the targeted bacterial cell. Using more than one antibiotic can result in interference between them and, as a worst case scenario, they can cancel each other.

- Most bacterial infections can be treated with a single antibiotic.

\section{Consequences of Improper Treatment}

- If the dose is too high or treatment times are too long, there is a danger of toxicity to the fish, frequently causing organ damage that may or may not be reversible.
- If the dose of antibiotic is too low or treatment time is too short, the bacteria will not be killed or weakened enough for the immune system of the fish to remove them, and this greatly increases the risk of the bacteria developing resistance to the antibiotic.

\section{Handling of Antibiotics}

- When preparing or administering any type of medication, it is always a good idea to wear gloves in order to avoid unnecessary exposure to the user.

- It is important to use antibiotics that are as fresh as possible and that stored properly.

- Antibiotics used after their expiration date, or that have been stored in hot and humid conditions, will have greatly reduced efficacy at best and, at worst, and may be toxic.

\section{Conclusion}

Misuse of antimicrobials or using of manure as a fertilizer in aquaculture may not only carry and disseminate some pathogenic food borne or zoonotic bacteria in a pond environment that could be also transmissible to human during culturing, rearing, harvesting, marketing, processing or consumption with health hazard but also may create multidrug- resistant strains and may produce fish of low quality and of shorter shelf-life.

\section{Recommendations}

- Frequent diagnosis of foodborne and zoonotic bacteria in pond environment is essential.

- Prevention and control of bacterial diseases in aquatic organisms is essential.

- Surveillance for antimicrobial resistance in humans and food animals is important.

- Detection to the changes in susceptibility of bacteria to the antimicrobials is essential.

- Control measures on the use of antimicrobial drugs should be implemented.

- The routine prophylactic use of antimicrobials should never substitute better hygiene.

- Prophylactic use of antimicrobials should be used only upon vaccination failure.

- Only non-human antibiotics may be available for performance enhancement.

- Overuse and misuse of antimicrobials in aquaculture should be restricted.

- The use of manure in aquaculture should be avoided or treated whenever possible.

\section{References}

1. Kapetsky J M (1995) A first look at the potential condritsution of warm water fish farming to food security in Africa.

2. Kitessa SM, Abeywardena M, Wijesundera C, Nichols PD (2014) DHAcontaining oilseed: a timely solution for the sustainability issues surrounding fish oil sources of the health-benefitting long-chain omega-3 oils. Nutrients 6: 2035-2058.

3. http://www.fao.org/fishery/sofia/en

4. Subasinghe RP, Bondad-Reantaso MG, McGladdery SE (2005) Aquaculture Development, Health and Wealth. Fisheries Dept, FAO, Rome, Italy. 
Citation: Aly SM, Albutti A (2014) Antimicrobials Use in Aquaculture and their Public Health Impact . J Aquac Res Development 5: 247.

Page 6 of 6

5. Teuber M (1999) Spread of antibiotic resistance with foodborne pathogens. Cellular and Molecular Life Sciences 56: 755-763.

6. Van den Bogaard AE, Willems R, London N, Top J, Stobberingh EE (2002) Antibiotic resistance of fecal enterococci in poultry, poultry farmers and poultry slaughterers. Journal of Antimicrobial Chemotherapy 49: 497-505.

7. Smith DL, Johnson JA, Harris AD, Furuno JP, Perencevich JG, et al., (2003) Assessing risks for a pre-emergent pathogen: virginiamycin use and the emergence of streptogramin resistance in Enterococcus faecium. Lancet Infectious Diseases 3: 241-249.

8. Nicole K (2008) Veterinary antibiotics in the aquatic and terrestrial Environment. Ecological Indicators 8: 1-13.

9. Levi SB (2001) Antibiotic resistance: Consequences of Inaction. Clin Infect Dis 33: S124-S129.

10. McKellar QA (1998) Antimicrobial resistance: a veterinary perspective BMJ 317: 610-611.

11. Walton JR (1983) Modes of action of growth promoting agents. Veterinary Research Communications 7: 17.

12. Mamun KZ, Shears P (1993) The Prevalence and genetics of resistance to commonly used antimicrobial agents in faecal enterobacteriaceae from children in Bangladesh. Epidemol Infect 110: 447-458.

13. Schmidt AS Bruun MS, Dalsgaard I, Pedersen K, Larsen JL (2000) Occurrence of antimicrobial resistance in fish-pathogenic and environmental bacteria associated with four Danish rainbow trout farms. Appl Environ Microbiol 66: 4908-4915.

14. Miranda CD, Zemelman R (2001) Antibiotic resistant bacteria in fish from the Concepción Bay, Chile. Mar Pollut Bull 42: 1096-1102.

15. Anon E (1999) Market Information 1998. Animal Health Products Association, Bangkok, Thailand.

16. DePaola A, Peeler JT, Rodrick GE (1995) Effect of oxytetracyclinemedicated feed on antibiotic resistance of gram-negative bacteria in catfish ponds. Appl Environ Microbiol 61: 2335-2340.

17. http://who.int/foodsafety/publications/micro/en/report.pdf
18. Tapiador DD, Henderson HF, Delmendo HN, Tsuitsuy H (1976) Freshwater fisheries and aquaculture in China. Food and Agriculture Organization of the United Nations, Rome, Italy.

19. Mitchell SK, James ML (2008) Risks to aquatic organisms posed by human pharmaceutical use. Sci Total Environ 389: 329-339.

20. Little DC, Edwards P (1999) Alternative strategies for livestock-fish integration with emphasis on Asia. Ambio 28: 118-124.

21. Alderman DJ, Hastings TS (1998) Antibiotic use in aquaculture: development of antibiotic resistance-potential for consumer health risks. Int J Food Sci Technol 33: 139-155.

22. Samuelsen OB, Torsvik V and Ervik A (1992) Long-range changes in oxytetracycline concentration and bacterial resistance towards oxytetracycline in a fish farm sediment after a medication. Sci Total Environ 114: 25-36.

23. Sandaa RA, Torsvik VL, Goksøyr J (1992) Transferable drug resistance in bacteria from fish-farm sediments. Can J Microbiol 38: 1061-1065.

24. Jacobsen P, Berglind L (1988) Persistence of oxytetracycline in sediments from fish farms. Aquaculture 70: 365-370.

25. http://who.int/foodsafety/publications/micro/en/report.pdf.

26. Ole EH, Hilde K, Kari G, Collignon P, Iddya K, et al., (2009) Human Health Consequences of Use of Antimicrobial Agents in Aquaculture. Clinical Infectious Diseases 49: 1248-1253.

27. Felipe CC, Henry PG, Alexandra T, Larisa I, Humberto D, et al., (2013) Antimicrobial use in aquaculture re-examined: its relevance to antimicrobial resistance and to animal and human health. Environmental Microbiology 15: 1917-1942.

28. Estefanía MA, Beatriz GS, Carlos A, Cristina C, Rosa DC, et al., (2013) Antimicrobial activity, antibiotic susceptibility and virulence factors of Lactic Acid Bacteria of aquatic origin intended for use as probiotics in aquaculture. BMC Microbiology 13: 15.

29. Aly SM (2009) Probiotics and aquaculture: A review. CAB Reviews: Perspectives in Agriculture, Veterinary Science, Nutrition and Natural Resources 4: 1-16. 